\title{
Demographic determinants of survival of people living with HIV attending an outpatient reference unit in the City of Três Lagoas, State of Mato Grosso do Sul, Brazil, in the period 1984-2009
}

\author{
Maria Angelina da Silva Zuque ${ }^{[1],[2]}$, Domingos Alves Meira ${ }^{[2]^{\dagger}}$ \\ and Carlos Magno Castelo Branco Fortaleza ${ }^{[2]}$
}

[1]. Departamento de Ciências Biológicas e Saúde, Universidade Federal de Mato Grosso do Sul, Três Lagoas, MS. [2]. Faculdade de Medicina de Botucatu, Departamento de Doenças Tropicais e Diagnóstico por Imagem, Universidade Estadual Paulista, Botucatu, SP. †in memoriam.

ABSTRACT

Introduction: While the incidence of HIV infection and AIDS is increasing in small Brazilian cities, epidemiological studies are often conducted in large urban centers. Methods: Our group conducted a retrospective analysis of survival determinants among 358 patients who attended a reference unit in a small city. Results: Death risk was lower among men that had sex with men, patients with an HIV-seropositive partner, and those admitted after highly active antiretroviral therapy (HAART) was available. Conclusions: The study documents the striking beneficial effect of HAART. The finding of other groups with improved survival may aid in the development of programmatic strategies.

Keywords: AIDS. Epidemiology. Survival.

Epidemiological reports on acquired immunodeficiency syndrome (AIDS) in Brazil have documented some major trends, namely, feminization, pauperization, and interiorization ${ }^{1}$. The last term refers to the increasing incidence of AIDS cases or human immunodeficiency virus (HIV) infection in small cities in inner Brazil, despite the stabilization and slow decrease of epidemics in large urban centers ${ }^{2}$. Data on this issue are compelling. Since the emergence of AIDS in Brazil, about 600,000 cases were notified to the health surveillance system (data available online at http://www2.aids.gov.br/cgi/deftohtm. exe?tabnet/aids.def). The proportion of patients residing outside capitals or metropolitan areas increased from $12.7 \%$ in 1984 to $31.6 \%$ in 1996 and $42.5 \%$ in 2009 . In the last edition of the AIDS Epidemiological Bulletin, only four capitals ranked among the 20 cities with the highest incidence of AIDS in the 1997-2009 period $^{3}$.

In view of this picture, the Brazilian Public Health System has supported the implementation of specialized outpatient units for AIDS care in several small and medium-sized cities. These units play an important role in the successful Brazilian AIDS program ${ }^{4}$.

Few epidemiological studies, however, have focused specifically on people living with HIV or AIDS in small cities. This is the case of survival analysis, which has been performed

\footnotetext{
Address to: Dr. Carlos Magno Castelo Branco Fortaleza. Depto. Doenças Tropicais e Diagnóstico por Imagem/FMB/UNESP. Endereço: Distrito de Rubião Junior s/n, 18618-970 Botucatu, SP, Brasil.

Phone: 5514 3811-6212; Fax: 5514 3815-9898

e-mail: cmfortaleza@uol.com.br

Received in 26/01/2011

Accepted in 08/08/2011
}

on whole-country health surveillance databases ${ }^{5,6}$ or with follow-up of cohorts from large cities ${ }^{7-10}$. These studies report longer survival times for men that have sex with men (MSM) and patients admitted without AIDS-defining conditions. Data on the relation between gender and survival were contradictory. On the other hand, there are no studies focusing on people living with HIV/AIDS in smaller cities. Differences in lifestyle and in AIDS epidemiology may account for divergent findings on that population.

The present study aimed to identify demographic determinants of survival among people living with HIV or AIDS attending a reference unit in a small city.

The study had a nonconcurrent (retrospective) cohort design, enrolling patients who were admitted to a reference outpatient unit.

The study was conducted in the Reference Unit for Sexual Transmitted Diseases and AIDS (RU-STD/AIDS) of the City of Três Lagoas, State of Mato Grosso do Sul, Brazil, which has approximately 100,000 inhabitants. The RU-STD/AIDS is a reference for HIV-positive and AIDS patients from Três Lagoas and several surrounding municipalities.

Patients who attended the RU-STD/AIDS from January 1984 through December 2009 were included in the study. Data were collected from medical charts. The study focused on demographic data from the moment of the patients' admission to the unit: gender, age, sexual orientation, educational level, use of illicit drugs, stable sexual partner (and his/her serological status), year of admission to the reference unit, and whether the patient was imprisoned. Our study focused specifically on demographic data, which were available for each patient who attended the RU-STD/AIDS since 1984. We chose not to include clinical and laboratory data. Since such data were poorly recorded before 
1996, we found that their inclusion would bias our results. We also chose to assess the availability of highly active antiretroviral therapy (HAART) at the moment of admission rather than the individual use of antiretrovirals. Our objective was to measure the effect of the availability of HAART at the time of admission to ambulatory care on overall survival. We assumed that the availability of better antiretroviral schemes was not the only improvement in AIDS care in the post-HAART era. Patients admitted after 1996 certainly benefited from a more standardized clinical and laboratory evaluation from the very beginning of their follow-up, and this could result in longer survival.

Statistical analysis was performed on SPSS 15.0 ( ) SPSS inc.). In a first step, an exploratory analysis of demographic data was performed using univariate and bivariate analysis. For the latter, we used the Chi-square test, the Mann-Whitney $\mathrm{U}$ test, and Kaplan-Meier survival curves, when indicated. The second step consisted in detailed survival analysis. The outcome of interest was death. Numeric and ordinal variables were dichotomized as follows: age (changed to above 30 years), educational level (complete fundamental study), and year of admission (previous or posterior to 1996, the year marking the introduction of HAART).
Data were submitted to bivariate and multivariate analysis using Cox proportional hazards models ${ }^{11}$. A stepwise forward (conditional) approach was applied to select variables for multivariate models. P-values of 0.05 and 0.1 were used as limits for entry and removal from the models ${ }^{12}$. As a counter-proof to forward selection, we built models using backward elimination of variables, under the same p-value parameters. Similar results were obtained with both strategies.

This study was approved by the reference Committee for Ethics in Research (Universidade Federal do Mato Grosso do Sul, protocol \#1163).

Data were obtained for all patients admitted to the RU-STD/AIDS in the study period. Among 358 study subjects, $60 \%$ were admitted in the HAART era. The median age was 30 years (range, 0 to 71). Males represented two thirds of patients, but their proportion fell from $74.8 \%$ in the pre-HAART era to $61.9 \%$ afterwards. Among males, $28.8 \%$ reported sex with men.

Table 1 summarizes the demographic data for the pre- and the HAART era.

Table 2 shows data from univariate and multivariate analysis. In the latter, the risk of death was significantly lower among MSM (Hazard Ratio $[\mathrm{HR}]=0.53,95 \%$ confidence interval

TABLE 1 - Demographic characteristics of people living with human immunodeficiency virus/acquired immunodeficiency syndrome admitted to ambulatory service in Três Lagoas (1984-2009).

\begin{tabular}{|c|c|c|c|c|c|}
\hline Characteristics & $\begin{array}{c}\text { Pre-HAART* } \\
n=143\end{array}$ & $\begin{array}{c}\text { HAART } \\
\mathbf{n}=\mathbf{2 1 5}\end{array}$ & $\begin{array}{l}\text { Total patients } \\
\qquad \mathbf{n}=\mathbf{3 5 8}\end{array}$ & OR $(95 \% C I)$ & $\mathbf{p}$ \\
\hline$\overline{\text { Female gender }(\%)^{\mathrm{a}}}$ & 25.2 & 38.1 & 33.0 & $1.81(1.15-2.94)$ & 0.01 \\
\hline Age median (years) ${ }^{b}$ & 28 & 31 & 30 & $\ldots$ & $<0.001$ \\
\hline Less than complete fundamental study $(\%)^{\mathrm{a}^{* *}}$ & 81.1 & 80.5 & 80.7 & $0.96(0.56-1.64)$ & 0.88 \\
\hline Intravenous drug users $(\%)^{\mathrm{a}}$ & 37.1 & 4.7 & 17.6 & $0.08(0.04-0.17)$ & $<0.001$ \\
\hline Men that have sex with men $(\%)^{\mathrm{a}^{* * *}}$ & 25.2 & 14.9 & 19.0 & $0.52(0.31-0.89)$ & 0.01 \\
\hline Residence in Três Lagoas $(\%)^{\mathrm{a}}$ & 83.2 & 79.5 & 81.0 & $0.78(0.45-1.36)$ & 0.38 \\
\hline Five year survival $(\%)^{\mathrm{c}}$ & 43.0 & 81.0 & 66.0 & $\ldots$ & $<0.001$ \\
\hline
\end{tabular}

HAART: after highly active antiretroviral therapy; OR $(\mathbf{9 5} \% \mathbf{C I})$ : odds ratio (95 percent confidence interval).

*baseline reference. ${ }^{* *}$ less than eight years of study. ${ }^{* * *}$ proportion measured in the whole database (men and women included). The overall proportion of this group among males only was $28.8 \%$. Statistical tests: ${ }^{\mathrm{a}}$ Chi-square test, ${ }^{\mathrm{b}}$ Mann-Whitney U-test, ${ }^{\mathrm{c}}$ Kaplan-Meier.

TABLE 2 - Results of bivariate and multivariate analysis of demographic determinants of survival among human immunodeficiency virus-seropositive patients.

\begin{tabular}{|c|c|c|c|c|}
\hline \multirow[b]{2}{*}{ Factors } & \multicolumn{2}{|c|}{ Bivariate analysis } & \multicolumn{2}{|c|}{ Multivariate analysis } \\
\hline & HR $(95 \% C I)$ & $\mathbf{p}$ & HR $(95 \% C I)$ & $\mathbf{p}$ \\
\hline Female gender & $1.31(0.90-1.89)$ & 0.15 & & \\
\hline Age $>30$ years & $0.95(0.68-1.33)$ & 0.79 & & \\
\hline Residing in Três Lagoas City & $0.79(0.53-1.19)$ & 0.26 & & \\
\hline Complete fundamental schooling* & $0.94(0.62-1.43)$ & 0.78 & & \\
\hline Men that have sex with men & $0.66(0.42-1.04)$ & 0.07 & $0.53(0.34-0.85)$ & 0.007 \\
\hline Multiple sexual patterns** & $0.50(0.21-1.23)$ & 0.13 & & \\
\hline Sexual partner known to be HIV seropositive & $0.62(0.37-1.04)$ & 0.07 & $0.58(0.35-0.98)$ & 0.04 \\
\hline Intravenous drug use & $1.61(1.10-2.33)$ & 0.01 & & \\
\hline Imprisoned patient & $1.28(0.63-2.63)$ & 0.52 & & \\
\hline Admitted to the unit in HAART era*** & $0.35(0.25-0.49)$ & 0.001 & $0.31(0.22-0.45)$ & $<0.001$ \\
\hline
\end{tabular}


$[\mathrm{CI}]=0.34-0.85, \mathrm{p}=0.007$ ), patients who had a stable relation with a partner known to be HIV seropositive (HR $=0.58$, $95 \% \mathrm{CI}=0.35-0.98, \mathrm{p}=0.04)$, and those admitted in the HAART era $(\mathrm{HR}=0.31,95 \% \mathrm{CI}=0.22-0.45, \mathrm{p}<0.001)$. Figure 1 displays survival curves for MSM and for HIV-positive partner.

The striking beneficial impact of HAART is widely recognized. The finding of improved survival in a cohort of patients from a small town in Middle-Western Brazil is not only consistent with this fact, but also demonstrates the success of the Brazilian AIDS Program in ensuring patients access to appropriate care. Nonetheless, knowing other determinants of survival in specific populations can help in the development of programmatic strategies. A comparison of our results with studies from large cities reveals both similarities and divergences.
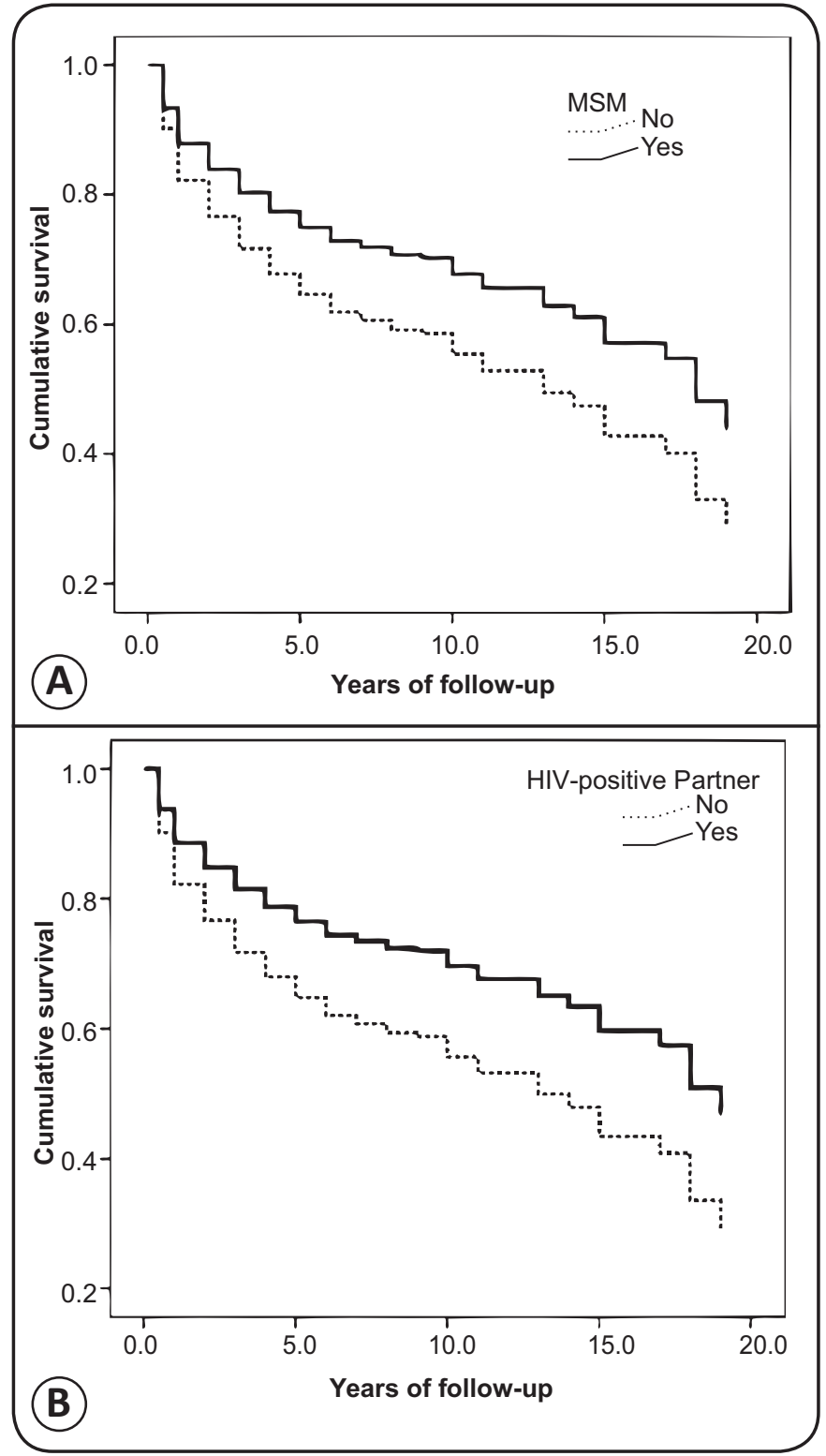

FIGURE 1 -Survival trends for men that have sex with men [A] and patients with HIV-seropositive partners [B] (Cox proportional hazards model).

HIV: human immunodeficiency virus; MSM: men that have sex with men.
We found no relation between gender and survival in our study. That association has been described in previous reports, even though authors have found contradictory results. Lower mortality for women was reported in studies conducted in Brazil ${ }^{9}$ and in African and Asian countries ${ }^{13}$. In contrast, women were found to have shorter survival in the follow-up of a cohort from Rio de Janeiro, Brazil ${ }^{7}$.

On the other hand, a better survival trend among MSM was documented in our study. A similar finding was reported in a Brazilian study that compared this group with intravenous drug users ${ }^{6}$. Because they were a group of high vulnerability to AIDS at the early stages of a pandemic, MSM showed great power of organization. This group played an important role in social movements that contributed to the institution of the AIDS program, including the free distribution of antiretroviral drugs. It is no surprise therefore that they present better prognosis, possibly due to early knowledge of HIV status and adherence to antiretroviral therapy. Our findings are also coherent with a recent report from the follow-up of a pool of 23 European and North American cohorts of antiretroviral-naïve subjects ${ }^{14}$. That study aimed to quantify a proportional increase in mortality rate in those patients, as compared with HIV-negative people. Among all subgroups studied, MSM had the lowest increase in mortality: $1.30,95 \% \mathrm{CI}=1.06-1.58$. Higher mortality raises were found among heterosexual groups $(2.94,95 \% \mathrm{CI}=2.28-3.73)$ and intravenous drug users $(9.37,95 \% \mathrm{CI}=8.13-10.75)$. Identical results were reported in the follow-up of a cohort of patients starting HAART in nine industrialized countries ${ }^{15}$.

The better survival performance among patients with a stable relation with an HIV-positive partner may be partly due to early diagnosis. It is possible, however, that mutual psychological support led to greater adherence to HAART. This is an interesting starting point for further research.

Finally, we should emphasize that survival was not related to age or schooling in our study. While patients in the RU-STD/ AIDS had a wide age variety, $80.7 \%$ of them had less than fundamental schooling, which means eight school years. It is possible that the cases of complete fundamental schooling were too few to warrant power to our statistical analysis.

Even though our study did not enroll a great number of patients, its value lies in the fact that it was conducted in a small town located far from major urban centers in the country. There are other limitations, such as the lack of adjustment for clinical and laboratory variables, as well as for individual use of HAART. As previously stated, this was a deliberate methodological choice, since we found that demographic data were more reliably recorded along the entire study period. Although this choice may have limited the scope of the inferences, it surely avoided biased results.

Epidemiological reports suggest an increasing incidence of HIV infection and AIDS in cities of medium and small size in the interior of Brazil ${ }^{2,3}$. Knowing the determinants of survival can aid in the development of effective strategies for health assistance to these populations. Besides documenting the striking improvement in survival for patients admitted to ambulatory AIDS in the post-HAART era, we identified MSM 
and people with stable HIV-seropositive partners as groups with better outcomes. A closer look at these groups, especially with regard to adherence to HAART and other AIDS-care issues, may be of substantial help in designing programmatic strategies to improve survival. Further studies with larger cohorts from small cities are needed to identify other particularities of AIDS epidemiology and survival determinants.

\section{CONFLICT OF INTEREST}

The authors declare that there is no conflict of interest.

\section{REFERENCES}

1. Brito AM, Castilho EA, Szwarcwald CL. Aids e infecção pelo HIV no Brasil: uma epidemia multifacetada. Rev Soc Bras Med Trop 2000; 34:207-217.

2. Grangeiro A, Escuder MM, Castilho EA. Magnitude and trend of the AIDS epidemic in Brazilian cities, from 2002 to 2006. Rev Saude Publica 2010; 44:430-440

3. Ministério da Saúde. Boletim epidemiológico Aids-DST. Brasília: Ministério da Saúde; 2010.

4. Nemes MI, Melchior R, Basso CR, Castanheira ER, Britto MT, Conway S. The variability and predictors of quality of AIDS care services in Brazil. BMC Health Serv Res 2009; 9:51.

5. Pereira EC, Schmitt AC, Cardoso MR, Aldrighi JM. Tendência da incidência e da mortalidade por aids em mulheres na transição menopausal e pós-menopausa no Brasil, 1996-2005. Rev Assoc Med Bras 2008; 54:422-425

6. Malta M, Bastos FI, Silva CM, Pereira GF, Lucena FF, Fonseca MG, et al. Differential survival benefit of universal HAART access in Brazil: a nationwide comparison of injecting drug users versus men who have sex with men. J Acquir Immune Defic Syndr 2009; 52:629-635.
7. Santoro-Lopes G, Harrison LH, Moulton LH, Lima LA, Pinho AM, Hofer C, et al. Gender and survival after AIDS in Rio de Janeiro, Brazil. J Acquir Immune Defic Syndr Hum Retrovirol 1998; 19:403-407.

8. Fonseca LA, Reingold AL, Casseb JR, Brigido LF, Duarte AJ. AIDS incidence and survival in a hospital-based cohort of asymptomatic HIV seropositive patients in São Paulo, Brazil. Int J Epidemiol 1999; 28:1156-1160.

9. Melo LS, Lacerda HR, Campelo E, Moraes E, Ximenes RA. Survival of AIDS patients and characteristics of those who died over eight years of Highly Active Antiretroviral Therapy, at a referral center in northeast Brazil. Braz J Infect Dis 2008; 12:269-277.

10. Pacheco AG, Tuboi SH, May SB, Moreira LF, Ramadas L, Nunes EP, et al. Temporal changes in causes of death among HIV-infected patients in the HAART era in Rio de Janeiro, Brazil. J Acquir Immune Defic Syndr 2009; 51:624-630.

11. Green MS, Symons MJ. A comparison of the logistic risk function and the proportional hazards model in prospective epidemiologic studies. J Chron Dis $1983 ; 36: 715-724$.

12. Greenland S. Modeling and variable selection in epidemiologic analysis. Am J Public Health 1989; 79:340-349.

13. Pujades-Rodríguez M, Balkan S, Arnould L, Brinkhof MA, Calmy A. AIDS Working Group of MSF. Treatment failure and mortality factors in patients receiving second-line HIV therapy in resource-limited countries. JAMA 2010; 304:303-312.

14. Lodwick RK, Sabin CA, Porter K, Ledergerber B, van Sighem A, CozziLepri A, et al. Death rates in HIV-positive antiretroviral-naive patients with CD4 count greater than 350 cells per microL in Europe and North America: a pooled cohort observational study. Lancet 2010; 376:340-345.

15. Zwahlen M, Harris R, May M, Hogg R, Costagliola D, WolfF, et al. Mortality of HIV-infected patients starting potent antiretroviral therapy: comparison with the general population in nine industrialized countries. Int J Epidemiol 2009; 38:1624-1633. 